\title{
Phylogenetic relationships of Pseudohynobius (Urodela, Hynobiidae) inferred from DNA barcoding analysis
}

\author{
Y.-Y. Zhao ${ }^{1 *}$, L.-N. Su ${ }^{3 *}$, Z.-M. Zhang' and X.-Y. Wang ${ }^{2}$ \\ ${ }^{1}$ Department of Genetics, Zunyi Medical University, Zunyi, China \\ ${ }^{2}$ College of Life Sciences, Shaanxi Normal University, Xi'an, China \\ ${ }^{3}$ Shaanxi Institute of Zoology, \\ Northwest Institute of Endangered Zoological Species, Xi'an, China \\ *These authors contributed equally to this study. \\ Corresponding author: X.-Y. Wang \\ E-mail: wangxiaoyang@snnu.edu.cn / relinker@hotmail.com
}

Genet. Mol. Res. 15 (2): gmr.15028155

Received August 8, 2015

Accepted November 26, 2015

Published July 15, 2016

DOI http://dx.doi.org/10.4238/gmr.15028155

\begin{abstract}
As a proven tool, DNA barcoding can identify species rapidly and unambiguously. In this study, we used mtDNA cyt b, COI, and 16s rRNA sequences of six species of Pseudohynobius, Protohynobius puxiongensis, Liua shihi, Ranodon sibiricus, and Pachyhynobius shangchengensis, to reconstruct the phylogenetic relationships using Bayesian inference and maximum likelihood methods. Approximate lineage divergence times were also estimated, the divergence between them was calculated to have taken place mainly in Miocene. Our results showed that: 1) PS. guizhouensis is an independent and valid species that is a sister species to Ps. kuankuoshuiensis; 2) five Pseudohynobius species formed a monophyletic group; 3) Ps. tsinpaensis is different from L. shihi, and should be classified as belonging to the Liua genus; and 4) Pr. puxiongensis is the sister lineage to all Pseudohynobius
\end{abstract}


species, and should therefore be named Pseudohynobius puxiongensis.

Key words: Pseudohynobius; Protohynobius puxiongensis; mtDNA COI; mtDNA cyt b; mtDNA 16s rRNA

\section{INTRODUCTION}

Molecular genetic approaches are widely used to study taxonomy, population genetics, and phylogenetic relationships of many organisms (Moritz and Hillis, 1996). The mitochondrion has some unique features, for example, maternal mode of inheritance, a high rate of evolution, and lack of recombination (Moritz et al., 1987). As a result, the mitochondrion is frequently used in comparative studies among closely related species and populations (Moritz et al., 1987). Molecular approaches, particularly those using mtDNA sequences, are often used for species delimitation (Knowlton, 2000). Although different genes in the mitochondrial genome have different rates of evolution, some more conserved gene regions within the genome have been used to study the deeper branches in amphibian evolution (Munasinghe et al., 2003). For DNA barcoding, mitochondrial cytochrome oxidase subunit I (COI), for example, has been shown to delimitate species rapidly and unambiguously. This region has also been used, for example, in genealogical reconstructions, forensics, and biodiversity surveys. Recently, a partial fragment of the mitochondrial COI gene has been used to barcode amphibian species in many studies (Che et al., 2012).

Barcoding of amphibians is essential in part because many species are now endangered (Che et al., 2012). Compared with other mitochondrial genes, COI is more frequently used in studies determining amphibian phylogenies or phylogeography. Therefore, other genes should be identified that could complement COI (Smith et al., 2008). In this study, we investigated the mtDNA cytochrome b (cyt b) and 16s rRNA genes as alternative molecular markers.

Pseudohynobius is an important group within the Hynobiidae. It was discovered and named by Fei and Ye (1982). Six species have been recorded in this genus so far; Ps. flavomaculatus (Fei and Ye, 1982), Ps. guizhouensis (Li et al., 2010), Ps. jinfo (Wei et al., 2009), Ps. kuankuoshuiensis (Xu et al., 2007), Ps. shuichengensis (Tian et al., 2006), and Ps. tsinpaensis (Hu et al., 1966). In addition to the above mentioned species, other species have been identified and named mainly based on morphological characters. cyt $\mathrm{b}$ was used by Li et al. (2010) to study five species of Pseudohynobius system development. Zeng et al. (2006) suggested that Ps. tsinpaensis should be called Liua tsinpaensis, based on a phylogenetic study of the Liua-Pseudohynobius complex using cyt b only.

Protohynobius puxiongensis, the only known five-toed hynobiid salamander, was discovered in the Hengduan mountain area (Liu, 1950; Zhao and Adler, 1993). It was described based on a single specimen and has never been found again, since its discovery in 1965. It was considered to belong to a new genus as well as a new subfamily. Because it had an internasal bone, a primitive character, the specimen was thought to represent a common ancestor of all other hynobiid salamanders. This conclusion bothered herpetologists for decades. In order to resolve the problem, based on living individuals of Pr. puxiongensis that were rediscovered at its type locality, Peng et al. (2010) reexamined the phylogenetic position of this species in relation to two Pseudohynobius species. They concluded that Pr. puxiongensis is, in fact, a sister group of the Pseudohynobius species. They also suggested that Pr. puxiongensis 
should be reclassified as a Pseudohynobius species and named Pseudohynobius puxiongensis (Peng et al., 2010). However, in their study, they only compared Pr. puxiongensis with two Pseudohynobius species.

In order to further examine the validity of the Pseudohynobius species, we recreated the phylogeny of six Pseudohynobius species. In addition, our aim was to determine whether Pr. puxiongensis is indeed the sister group of all the known Pseudohynobius species or whether it was nested within the Pseudohynobius. This was done based on partial sequences of mtDNA COI, mtDNA cyt $b$, and 16s rRNA genes.

\section{MATERIAL AND METHODS}

\section{Sequence data}

We downloaded mtDNA cyt b, COI, and 16s rRNA sequences of Pr. puxiongensis, $L$. shihi, Ranodon sibiricus, Pachyhynobius shangchengensis, and the six Pseudohynobius species from GenBank (Table 1). Pa. shangchengensis and $R$. sibiricus were included as the outgroup.

Table 1. Accession numbers of all species included in this study that were downloaded from GenBank.
\begin{tabular}{l|l|l|l}
\hline \multirow{2}{*}{ Species } & \multicolumn{1}{l}{ Accession numbers } \\
\cline { 2 - 4 } & mtDNA cyt b & mtDNA COI & mtDNA 16s rRNA \\
\hline Pseudohynobius guizhouensis & JX867277.1 & JN165828.1 & JN165944.1 \\
\hline Pseudohynobius kuankuoshuiensis & JX867278.1 & JN165830.1 & JN165946.1 \\
\hline Pseudohynobius shuichengensis & FJ532060.1 & FJ532060.1 & FJ532060.1 \\
\hline Pseudohynobius flavomaculatus & FJ532059.1 & FJ532059.1 & FJ532059.1 \\
\hline Pseudohynobius jinfo & DQ335723.1 & JN165827.1 & JN165943.1 \\
\hline Pseudohynobius tsinpaensis & DQ333813.1 & DQ333813.1 & DQ333813.1 \\
\hline Protohynobius puxiongensis & FJ532058.1 & FJ532058.1 & JN165950.1 \\
\hline Liua shihi & $107991059: 14180-15321$ & $107991059: 5352-6893$ & $107991059: 1074-2671$ \\
\hline Ranodon sibiricus & $21450026: 14182-15322$ & $21450026: 5355-6905$ & $21450026: 1077-2676$ \\
\hline Pachyhynobius shangchengensis & $107991129: 14169-15310$ & $107991129: 5330-6880$ & $107991129: 1074-2652$ \\
\hline
\end{tabular}

The sequences were aligned with ClustalX v. 1.83 (Chenna et al., 2003). The aligned sequences were edited using BioEdit v. 7.0.9.0 (Hall, 1999). The total number of sites (excluding sites with gaps/missing data) was 1802, of which $583 \mathrm{bp}$ were sequenced for the COI gene, 754 bp for the cyt b gene, and 465 bp for the 16s rRNA gene.

\section{Phylogenetic analyses}

The phylogenetic relationships among the species were estimated using maximum likelihood (ML) analyses in PHYML v. 3.0 (Guindon et al., 2010), as well as Bayesian ML analyses with 3,000,000 generations in MrBayes v. 3.2 (Ronquist et al., 2012). To find the best-fitting substitution model we used MODELTEST (Posada and Crandall, 1998) and MrModeltest v2 (Nylander, 2004). A GTR $+\mathrm{I}+\mathrm{G}$ model was adopted in both the ML and Bayesian analyses. Branch support for the ML analyses was evaluated with a non-parametric bootstrap analysis (1000 replicates).

\section{Divergence time estimate}

The partial mtDNA sequences were used to estimate the approximate divergence 
times of the species included in this study using BEAST v. 1.4.7 (Drummond and Rambaut, 2007). All sequences including the outgroups and a Bayesian Markov chain Monte Carlo approach with an uncorrelated log-normal relaxed molecular clock were used in the analysis. Two independent runs, each composed of 120 million generations, were performed. The results were visualized in Tracer V1.6 (Rambaut and Drummond, 2013), to test for stationarity. We used LogCombiner 1.4.7 (Drummond and Rambaut, 2007) to combine both runs, TreeAnnotator 1.4.7 (Drummond and Rambaut, 2007) to annotate tree information, and FigTree 1.4.2 (Rambaut, 2014) to visualize the final tree information.

Weisrock et al. (2001) proposed a molecular evolutionary rate of the mitochondrial genome of hynobiids ( $0.64 \%$ per myr per lineage). Therefore, $0.64 \%$ per Myr per lineage was used to estimate the divergence between the species.

\section{RESULTS}

\section{Phylogenetic analyses}

The tree topologies of the ML and Bayesian analyses were identical (Figures 1 and 2). With respect to the outgroup, the Pseudohynobius species formed a monophyletic group. Ps. tsinpaensis and $L$. shihi formed a separate branch. Based on these data, we were able to conclude that: 1) Ps. guizhouensis is an independent and valid species, which is a sister species to Ps. kuankuoshuiensis; 2) five species of Pseudohynobius formed a monophyletic group; 3) Ps. tsinpaensis is different from and a sister species to L. shihi; 4) Pr. puxiongensis is sister lineage to all the Pseudohynobius species.

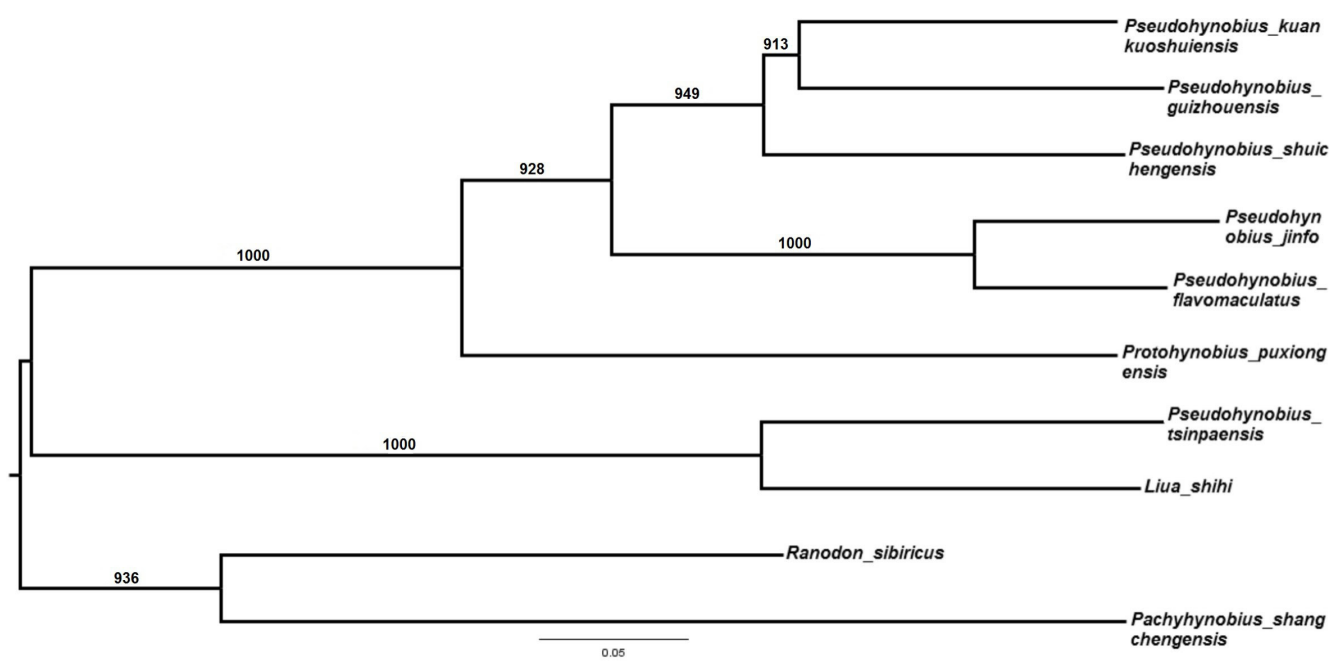

Figure 1. Maximum likelihood tree based on mtDNA sequences of six species of Pseudohynobius, Protohynobius puxiongensis, and Liua shihi. Ranodon sibiricus and Pachyhynobius shangchengensis are included as outgroup. Numbers above the branches represent the bootstrap values. The scale bar represents the number of substitutions per site. 


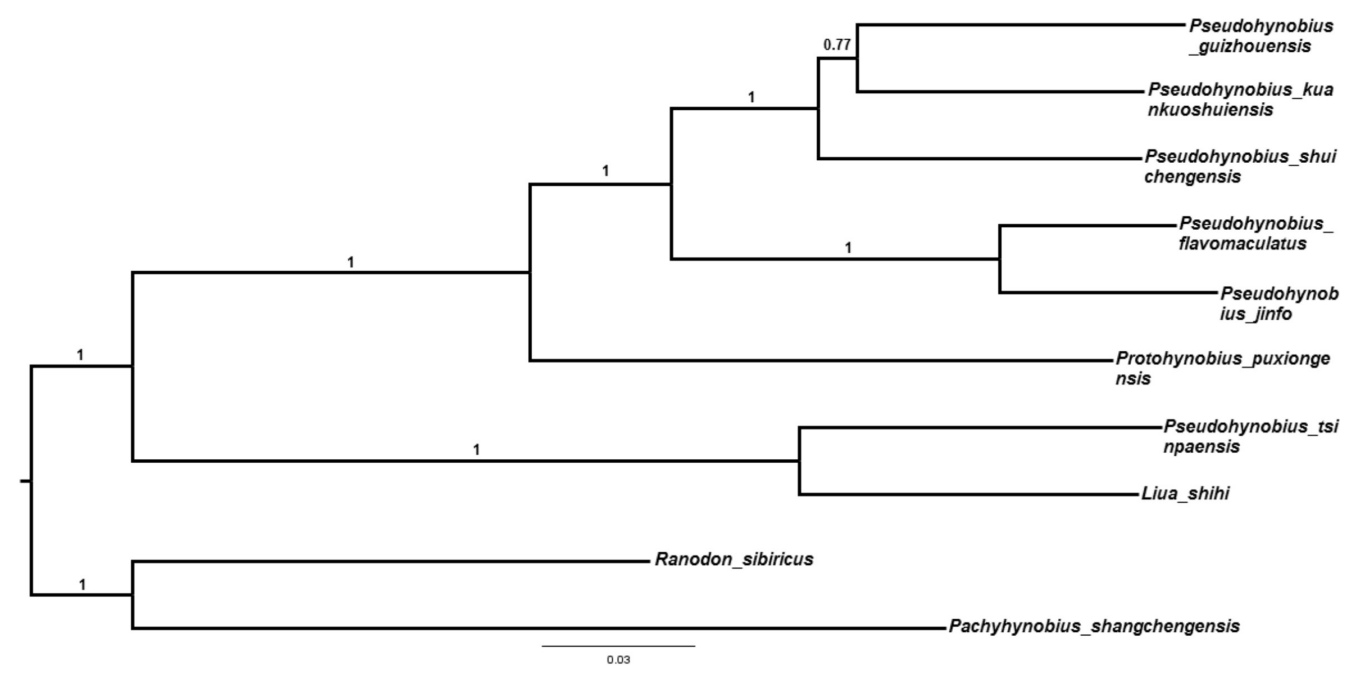

Figure 2. Bayesian tree based on mtDNA sequences of six species of Pseudohynobius, Protohynobius puxiongensis, and Liua shihi from China. The tree is rooted with sequences from Ranodon sibiricus and Pachyhynobius shangchengensis. Values above the branches indicate Bayesian posterior probabilities. The scale bar represents the number of substitutions per site.

\section{Divergence time estimate}

When in geological time the divergences happened, and the results of the BEAST analysis showed that the divergence times among Ps. flavomaculatus, Ps. guizhouensis, Ps. jinfo, Ps. kuankuoshuiensis, and Ps. shuichengensis all occurred at the end of Miocene (Figure 3).

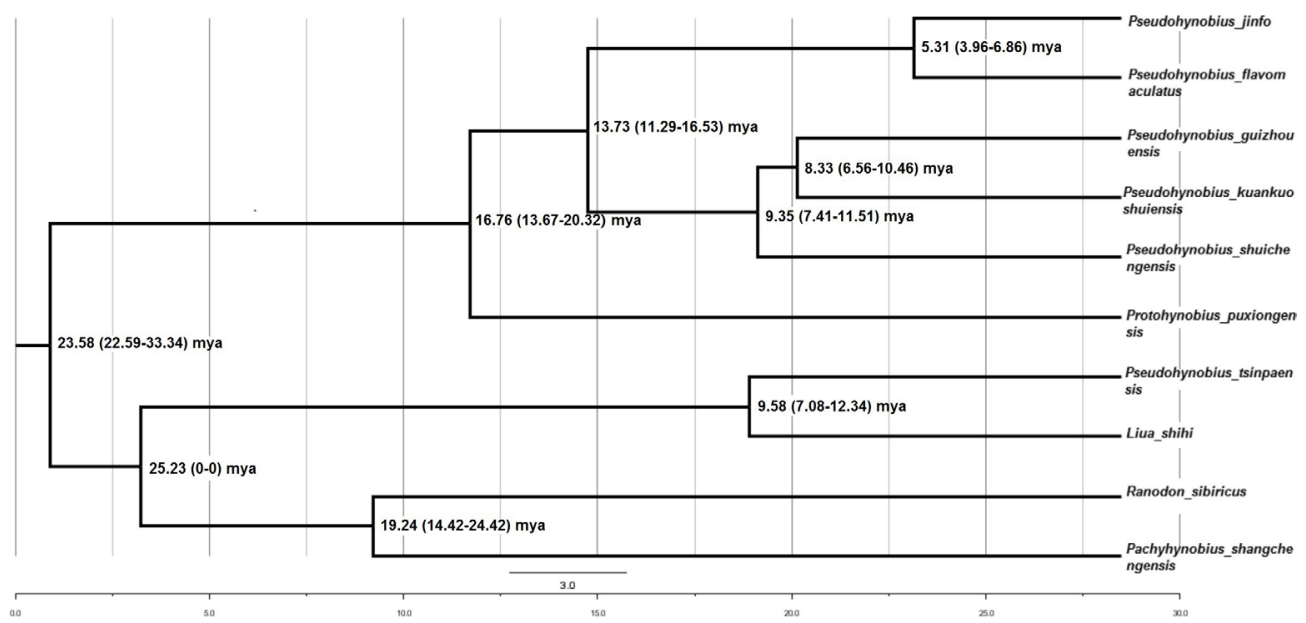

Figure 3. Phylogenetic neighbor joining tree based on mtDNA sequences of six species of Pseudohynobius, Protohynobius puxiongensis, and Liua shihi in China, rooted with two sequences from Ranodon sibiricus and Pachyhynobius shangchengensis. Numbers above the branches represent the bootstrap values and the values at the nodes are the exact divergence times with the $95 \%$ highest posterior density interval as estimated by BEAST. The scale bar represents the number of substitutions per site. 


\section{DISCUSSION}

\section{Validity of the Pseudohynobius species}

The divergence times between each species pair was large, so we believe that these five Pseudohynobius species are valid. Based on the phylogenetic analyses, we found that Ps. tsinpaensis and L. shihi formed a branch separate from the other five Pseudohynobius species and Pr. puxiongensis. The divergence time between these species occurred at the end of Oligocene 25.23 mya (Figure 3). This indicates that Ps. tsinpaensis and L. shihi are closely related and that Ps. tsinpaensis should be classified into the Liua genus, as suggested previously (Zeng et al., 2006; Zhang et al., 2006). Hence, the Liua genus should contain two species: L. shihi and L. tsinpaensis.

\section{Validity of Protohynobius puxiongensis}

The phylogenetic analyses showed that Pr. puxiongensis and the five remaining Pseudohynobius species form a single branch, indicating a close relationship between them (Figures 1 and 2). The divergence time between Pr. puxiongensis and the five Pseudohynobius species was calculated to have taken place in the middle of Miocene and Pliocene, at around 16.76 mya (Figure 3). Hence, it can be concluded that Pr. puxiongensis is a sister lineage to all Pseudohynobius species. Protohynobius puxiongensis should therefore be named Pseudohynobius puxiongensis (Figures 1 and 2), as suggested by Peng et al. (2010).

\section{Conservation of Pseudohynobius species}

All Pseudohynobius species have very specific living condition requirements (Xiong et al., 2010) and the distribution range of each of the Pseudohynobius species is narrow. For example, Ps. kuankuoshuiensis is only found in the Kuankuoshui Reserve of the Guizhou Province (Xu et al., 2007), Ps. shuichengensis is only distributed within the Shuicheng county of the Guizhou Province (Tian et al., 2006), and Ps. jinfo is found only in the Jinfo mountains outside of Chongqing city (Wei et al., 2009). Many factors have been found to cause a drastic decline in the number of Pseudohynobius species, including climate change, environmental destruction, and intensified human activity (Xiong et al., 2010). Therefore, these species are in need of urgent protection and our best efforts are needed to protect the Pseudohynobius genus from extinction.

\section{ACKNOWLEDGMENTS}

Research supported by the Doctoral Fund of Zunyi Medical University (\#F-702).

\section{REFERENCES}

Che J, Chen HM, Yang JX, Jin JQ, et al. (2012). Universal COI primers for DNA barcoding amphibians. Mol. Ecol. Resour. 12: 247-258. http://dx.doi.org/10.1111/j.1755-0998.2011.03090.x

Chenna R, Sugawara H, Koike T, Lopez R, et al. (2003). Multiple sequence alignment with the Clustal series of programs. Nucleic Acids Res. 31: 3497-3500. http://dx.doi.org/10.1093/nar/gkg500 
Drummond AJ and Rambaut A (2007). BEAST: Bayesian evolutionary analysis by sampling trees. BMC Evol. Biol. 7: 214. http://dx.doi.org/10.1186/1471-2148-7-214

Fei L and Ye CY (1982). A new species of salamander from Hubei Province-Hynobius flavomaculatus. Acta Zootaxon. Sin. 7: 225-228.

Guindon S, Dufayard JF, Lefort V, Anisimova M, et al. (2010). New algorithms and methods to estimate maximumlikelihood phylogenies: assessing the performance of PhyML 3.0. Syst. Biol. 59: 307-321. http://dx.doi.org/10.1093/ sysbio/syq010

Hall TA (1999). BioEdit: a user-friendly biological sequence alignment editor and analysis program for Windows 95/98/ NT. Nucleic Acids Symp. Ser. 41: 95-98.

Hu SQ, Zhao EM and Liu CZ (1966). Amphibian and reptile from Qinling and Dabashan. Acta Zootaxon. Sin. 18: 57-89.

Knowlton N (2000). Molecular genetic analyses of species boundaries in the sea. Hydrobiologia 420: 73-90. http://dx.doi. org/10.1023/A:1003933603879

Li S, Tian YZ and Gu XM (2010). A new species of the Genus Pseudohynobius (Caudata, Hynobiidae) from Guizhou, China. Acta Zootaxon. Sin. 35: 407-412.

Liu CC (1950). Amphibians of western China. Fieldiana Zool. Mem. 2: 1-400. http://dx.doi.org/10.5962/bhl.part.4737

Moritz C and Hillis DM (1996). Molecular systematics: context and controversies. In: Molecular systematics (Hillis DM, Moritz C and Mable BK, eds.). 2nd edn. Sinauer Associates, Sunderland, 1-13.

Moritz C, Dowling TE and Brown WM (1987). Evolution of animal mitochondrial DNA: relevance for population biology and systematics. Annu. Rev. Ecol. Syst. 18: 269-292. http://dx.doi.org/10.1146/annurev.es.18.110187.001413

Munasinghe H, Murphy N and Austin C (2003). Utility of mitochondrial DNA sequences from four gene regions for systematic studies of Australian freshwater crayfish of the Genus Cherax (Decapoda: Parastacidae). J. Crustac. Biol. 23: 402-417. http://dx.doi.org/10.1163/20021975-99990350

Nylander JAA (2004). MrModeltest v2. Program distributed by the author. Evolutionary Biology Centre, Uppsala University, Sweden.

Peng R, Zhang P, Xiong JL, Gu HJ, et al. (2010). Rediscovery of Protohynobius puxiongensis (Caudata: Hynobiidae) and its phylogenetic position based on complete mitochondrial genomes. Mol. Phylogenet. Evol. 56: 252-258. http:// dx.doi.org/10.1016/j.ympev.2009.12.011

Posada D and Crandall KA (1998). MODELTEST: testing the model of DNA substitution. Bioinformatics 14: 817-818. http://dx.doi.org/10.1093/bioinformatics/14.9.817

Rambaut A (2014). FigTree, tree figure drawing tool, version 1.4.2. Available at [http://tree.bio.ed.ac.uk/]. Accessed July $9,2015$.

Rambaut A and Drummond AJ (2013). Tracer. v1.6.0. Available at [http://tree.bio.ed.ac.uk/]. Accessed December 11, 2014.

Ronquist F, Teslenko M, van der Mark P, Ayres DL, et al. (2012). MrBayes 3.2: efficient Bayesian phylogenetic inference and model choice across a large model space. Syst. Biol. 61: 539-542. http://dx.doi.org/10.1093/sysbio/sys029

Smith MA, Poyarkov NA, Jr. and Hebert PD (2008). DNA BARCODING: CO1 DNA barcoding amphibians: take the chance, meet the challenge. Mol. Ecol. Resour. 8: 235-246. http://dx.doi.org/10.1111/j.1471-8286.2007.01964.x

Tian YZ, Li S and Gu XM (2006). A new species of genus Pseudohynobius (Caudata: Hynobiidae) -Pseudohynobius shuichengensis. Acta Zool. Sin. 52: 522-527.

Wei G, Xiong JL, Hou M and Zeng XM (2009). A new species of hynobiid salamander (Urodela: Hynobiidae: Pseudohynobius) from Southwestern China. Zootaxa 2149: 62-68.

Weisrock DW, Macey JR, Ugurtas IH, Larson A, et al. (2001). Molecular phylogenetics and historical biogeography among salamandrids of the "true" salamander clade: rapid branching of numerous highly divergent lineages in Mertensiella luschani associated with the rise of Anatolia. Mol. Phylogenet. Evol. 18: 434-448. http://dx.doi. org/10.1006/mpev.2000.0905

Xiong JL, Zhu WW and Sun P (2010). The systematic taxonomy of Chinese endemic genera in Hynobiidae. Agric. Sci. Technol. 11: 55-58.

Xu N, Zeng XM and Fu JZ (2007). A new species of the genus Pseudohynobius (Caudata, Hynobiidae) from China. Acta Zootaxon. Sin. 32: 230-233.

Zeng XM, Fu JZ, Chen LQ, Tian YZ, et al. (2006). Cryptic species and systematics of the hynobiid salamanders of the Liua-Pseudohynobius complex: Molecular and phylogenetic perspectives. Biochem. Syst. Ecol. 34: 467-477. http:// dx.doi.org/10.1016/j.bse.2006.01.006

Zhang P, Chen YQ, Zhou H, Liu YF, et al. (2006). Phylogeny, evolution, and biogeography of Asiatic salamanders (Hynobiidae). Proc. Natl. Acad. Sci. USA 103: 7360-7365. http://dx.doi.org/10.1073/pnas.0602325103

Zhao EM and Adler K (1993). Herpetology of China. Society for the Study of Amphibians and Reptiles, Oxford. 